\title{
Sitagliptin Results in a Decrease of Truncated Apolipoprotein C1
}

Nicole E. B. Skinner $\cdot$ Matthew S. Wroblewski $\cdot$ Julie A. Kirihara

Gary L. Nelsestuen · Elizabeth R. Seaquist

To view enhanced content go to www.diabetestherapy-open.com

Received: June 17, 2015 / Published online: July 22, 2015

(C) The Author(s) 2015. This article is published with open access at Springerlink.com

\section{ABSTRACT}

Apolipoprotein C1 (ApoC1) is a component of multiple lipoproteins where it performs a variety of roles in lipid metabolism and transport. ApoC1 exists as both full-length and truncated isoforms. Truncation of ApoC1 has been postulated to result from the action of dipeptidyl peptidase-4 (DPP-4), the target of a new class of diabetes drugs that includes sitagliptin phosphate. In this study, we sought to determine if oral administration of sitagliptin altered the proportion of ApoC1 isoforms circulating in humans. Results indicated a dramatic change in ApoC1 truncation,

Electronic supplementary material The online version of this article (doi:10.1007/s13300-015-0123-1) contains supplementary material, which is available to authorized users.

N. E. B. Skinner

Department of Laboratory Medicine and Pathology, University of Minnesota, Minneapolis, MN, USA

M. S. Wroblewski · J. A. Kirihara - G. L. Nelsestuen Department of Biochemistry, Molecular Biology and Biophysics, University of Minnesota, Minneapolis, $\mathrm{MN}$, USA

E. R. Seaquist ( $\square)$

Department of Medicine, University of Minnesota, Minneapolis, MN, USA

e-mail: seaqu001@umn.edu consistent with a high level of DPP-4 inhibition by sitagliptin.

Funding: University of Minnesota, Minneapolis, MN, USA.

Keywords: Apolipoprotein $\quad$ C1; Mass spectrometry; Sitagliptin

\section{INTRODUCTION}

Apolipoprotein C1 (ApoC1) has a variety of roles in lipid metabolism and transport. It is involved in maintaining and stabilizing highdensity lipoprotein (HDL) structure [1], lipase enzyme regulation [1-3], and inhibition of very low-density lipoprotein (VLDL) binding to both the low-density lipoprotein (LDL) receptor and the LDL receptor-related protein $[4,5]$. It also inhibits cholesterol ester transferase, which shuttles cholesterol esters and triglycerides between lipoproteins [6]. The overall effects of ApoC1 activity are complex and poorly understood. Overexpression of human ApoC1 in mice produces hyperlipidemia [2, 7], suggesting that it increases serum lipid levels. However, in the same mouse models, 
overexpression also protects against diabetes and obesity. In humans, polymorphisms in the ApoC1 promoter have been linked to decreased ApoC1 expression as well as a hereditary hyperlipidemia syndrome (familial dysbetalipoproteinemia), cardiovascular disease, and Alzheimer's disease [8-12].

ApoC1 exists in vivo as a full-length as well as in a truncated (ApoC1') isoform, lacking the two N-terminal amino acids, threonine and proline. While the ratio of full-length to truncated protein (ApoC1/ApoC1') has been shown to differ between individuals, it remains highly stable within a given individual over time [13]. The function of fulllength versus truncated protein as well as the significance of the ratio between the two has yet to be elucidated [14]. However, biophysical analysis revealed maximum flexibility and availability of the amino terminus, making this site a candidate for protein-protein interactions [15].

The first-known structural polymorphism of ApoC1 was recently identified [16]. The polymorphism, a threonine to serine substitution at position 45 (T45S) found only in individuals with American Indian or Mexican ancestry, resulted in increased levels of truncated protein and decreased levels of total ApoC1. The initial study found that the mutation was associated with increased distribution to VLDL and a higher body mass index (BMI). A later study of the Oji-Cree community in Canada found that the presence of the polymorphism was associated with decreased plasma leptin and decreased body fat [17]. While both reports showed a physiological effect, they appeared contradictory. However, the two studies were of dissimilar subjects, with average age and BMI of $44 \pm 10$ years and $29 \pm 6 \mathrm{~kg} / \mathrm{m} \mathrm{[18]} \mathrm{vs.}$ $25 \pm 12$ years and $25 \pm 5 \mathrm{~kg} / \mathrm{m}$ [17]. The polymorphism of the promotor region is associated with decreased plasma ApoC1 [11] and with increased Alzheimer's disease [19].

The enzyme responsible for cleavage of fulllength ApoC1 to its truncated isoform has not been definitively identified, but has been suggested to be dipeptidyl peptidase-4 (DPP-4), a widely distributed serine protease with many known substrates, including cytokines, chemokines, growth factors, and neuropeptides [20]. While this enzyme prefers cleavage of amino terminal $\mathrm{NH}_{2}$-X-Pro with optimum cleavage of $\mathrm{NH}_{2}$-Ala-Pro [14] it also cleaves a large number of other sequences [21, 22] in an apparent protein-dependent manner. Human ApoC1 contains $\mathrm{NH}_{2}$-Thr-Pro, a suitable substrate for DPP-4 [21]. In vitro assays have shown that DPP-4 is capable of cleaving both the wild-type (T45) and variant (S45) ApoC1, but that S45 ApoC1 is cleaved more readily, which is consistent with the higher proportion of cleaved protein found in individuals with the polymorphism [16].

Among the many known DPP-4 substrates is the gastrointestinal hormone, glucagon-like peptide-1 (GLP-1). GLP-1 acts to increase insulin secretion, decrease glucagon production, and slow gastric emptying following meals, but becomes inactivated by cleavage with DPP-4 [20, 23]. For this reason, DPP-4 has become a target for management of type 2 diabetes. The drug sitagliptin phosphate is an FDA-approved DPP-4 inhibitor shown to lower mean blood glucose levels in diabetics by augmenting GLP-1 levels [24]. Given the extensive correlation of ApoC1 to disease and the unexplained presence of two isoforms of the protein, it is of interest to determine the effect of sitagliptin on ApoC1 truncation.

This study reports the results of healthy nondiabetics who were treated with sitagliptin to compare ApoC1/ApoC1' ratios before and after 
treatment. A significant decrease in truncation followed treatment, thus providing evidence that DPP-4 is responsible for cleavage of ApoC1 in humans in vivo.

\section{METHODS}

Five healthy volunteers (2F/3 M, age $31.2+8.6$, BMI $23.2+3.1$ ) received 3-day administration of sitagliptin (100 mg/day). Blood was drawn into citrate anticoagulant at baseline and 3 days. Mouse and dog plasmas were purchased from Innovative Research, Novi, MI, USA. The ratio of full-length to truncated ApoC1 was determined by matrix-assisted laser desorption ionization-time of flight (MALDITOF) mass spectrometry as described elsewhere [25] before and after drug administration. Plasma ApoC1 concentrations were determined with a commercial ELISA kit (Abcam, Cambridge, MA). Data were analyzed using Prism v5.0c (GraphPad Software, La Jolla, CA). Statistical analyses were performed using the Wilcoxon matched pairs signed pairs test.

This study was approved by the Institutional Review Board of the University of Minnesota. All procedures followed were in accordance with the ethical standards of the responsible committee on human experimentation at the University of Minnesota and with the Helsinki Declaration of 1975, as revised in 2013. Informed consent was obtained from all patients for being included in the study.

\section{RESULTS}

The method used in this study has at least two unique properties. First is that carefully controlled reverse phase extraction of diluted plasma with analysis by MALDI-TOF mass spectrometry results in a small number of intense peaks. The second is that the ratios of protein isoforms found the spectrum are extremely reproducible. The ratio of fulllength to truncated ApoC1 is an example (Fig. 1). The mass difference in these peaks $(m / z=6632-6434=198 \mathrm{amu})$ corresponds to loss of Thr-Pro, the expected cleavage of the amino terminal dipeptide. There are no other known modifications that are consistent with this mass change. This isoform ratio was measured before and after sitagliptin administration (Fig. 1). An average $2.5 \pm 0.28$ fold increase in this ratio was observed (before average $=2.05+0.22$, range $1.76-2.2 ;$ after average $=5.1+0.9, \quad$ range $3.96-6.25)$, corresponding to an average 50\% decline of the truncated ApoC1 (33\% to 17\%). Prior studies of plasma drawn from healthy individuals at baseline and again at 3 years showed stable ratios of full-length to truncated ApoC1 with an average of $0.96 \pm 0.07$ (ratio at

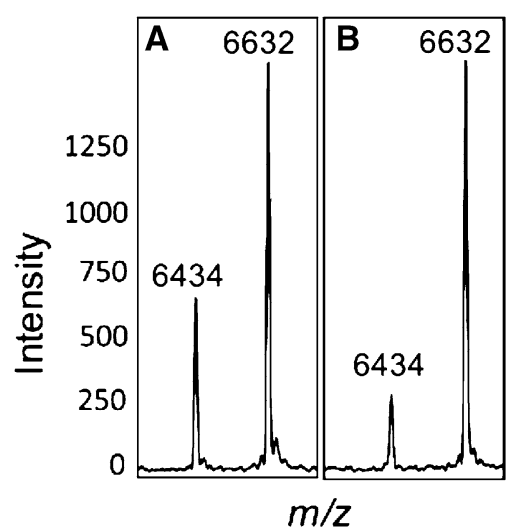

Fig. 1 Effect of sitagliptin treatment on isoforms of ApoC1. MALDI-TOF profile of ApoC1 from subject 1 prior to (a) and after (b) treatment with sitagliptin. The peak at $m / z=6632$ corresponds to full-length ApoC1 while the peak at 6434 is truncated ApoC1. ApoC1 Apolipoprotein $\mathrm{C} 1, M A L D I-T O F$ matrix-assisted laser desorption ionization-time of flight 


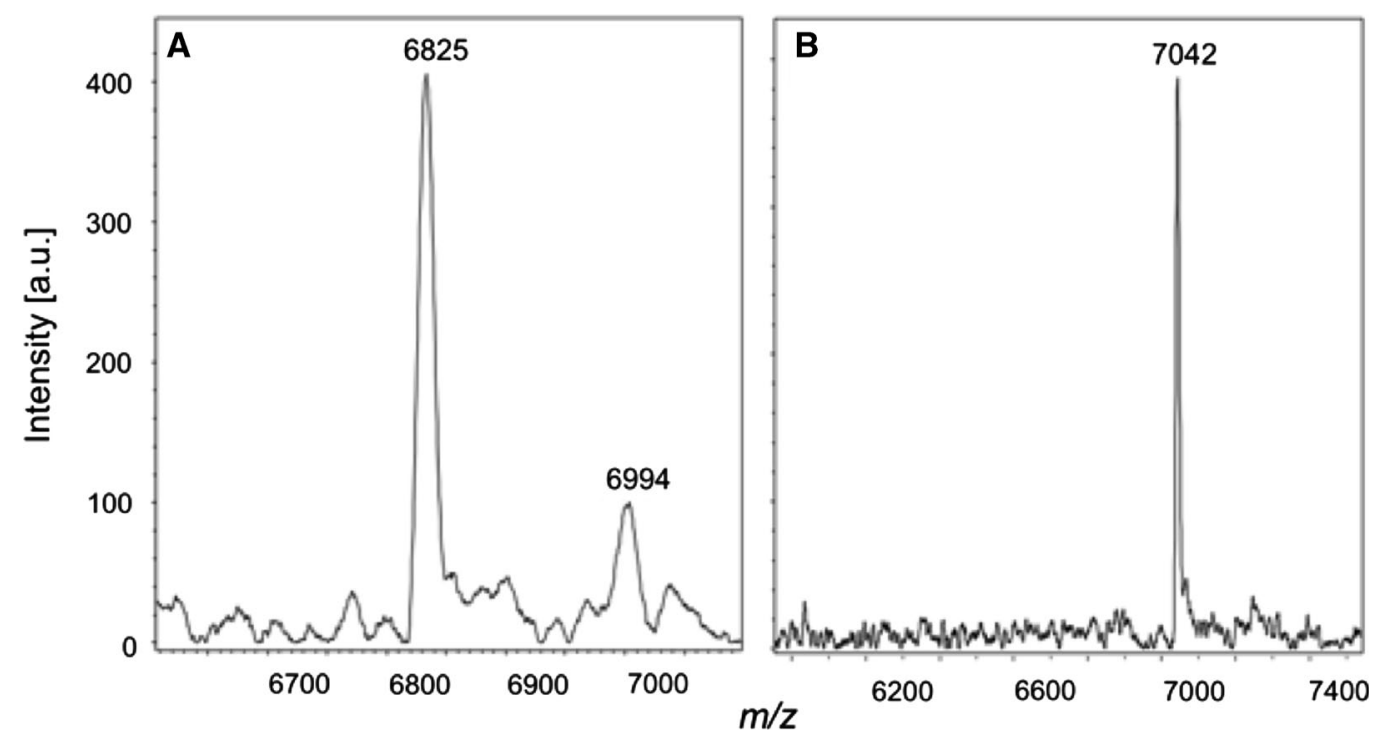

Fig. 2 ApoC1 and $\mathrm{ApoC}^{\prime}$ peak intensities in mouse and dog plasmas. a MALDI-TOF profile showing an expanded view of the ApoC1 region from a representative mouse plasma sample. b MALDI-TOF profile showing an expanded view of the 3 year/ratio at baseline [25]). Thus, the change observed following sitagliptin was exceptional, corresponding to 35 standard deviations greater than normal variation. This also occurred in only 3 days.

Although truncation may serve several purposes, one may be protein turnover. For example, lower ApoC1 in persons with the T45S variant would be consistent with enhanced removal of the truncated protein from the circulation. If correct, inhibition of truncation due to sitagliptin should result in decreased turnover and a corresponding increase of total ApoC1. However, plasma ApoC1 concentrations were unchanged after sitaglipin administration as determined with a commercial ELISA kit (Abcam, Cambridge, MA) (average ratio for each individual before/after drug $=0.99+0.05$, range among subjects $=36-53 \mu \mathrm{g}$ ApoC $1 / \mathrm{mL}$ ) .

Additional evidence for ApoC1 cleavage by DPP-4 was obtained by species comparisons. Mouse ApoC1 contains the putative optimum DPP-4 substrate sequence of $\mathrm{NH}_{2}$-Ala-Pro. Earlier
ApoC1 region from a representative dog plasma sample. $A p o C 1$ Apolipoprotein C1, $A p o C 1^{\prime}$ truncated isoform of Apolipoprotein C1, MALDI-TOF matrix-assisted laser desorption ionization-time of flight

studies by electrospray ionization mass spectrometry reported a preponderance of truncated ApoC1 in the mouse [26]. MALDI-TOF profile analysis by the method used for human ApoC1 confirmed this finding with a major peak at $m / z=6825$, corresponding to truncated mouse ApoC1 and only trace levels of a component corresponding to the full-length form at $\mathrm{m}$ / $Z=6994$ (Fig. 2a). In contrast, canine ApoC1 contains the amino terminal sequence of $\mathrm{NH}_{2}$ Ala-Gly, a poorer substrate for DPP-4 [21]. Earlier studies by electrospray mass spectrometry reported a single isoform of canine ApoC1 at $m / z=7042$ [27], corresponding to the full-length protein. In agreement, MALDI-TOF mass spectrometry by the method outlined in this study showed a single peak at the $m / z$ corresponding to full-length canine ApoC1 (Fig. 2b).

\section{DISCUSSION}

Overall, this study supported the conclusion that truncation of ApoC1 arises from the action 
of DPP-4, as hypothesized. This was indicated by a dramatic decline of truncated ApoC1 following sitagliptin administration in each of the five subjects. Extensive prior studies found no basis for this large change among the healthy population [25]. This interpretation was based on an assumed specificity of sitagliptin for DPP-4. Thus, a more precise conclusion was that sitagliptin inhibited truncation of ApoC1. Consequently, change in the ratio of ApoC1 isoforms is an unappreciated side effect of DPP-4 inhibitors.

The decline of truncated protein was consistent with the target level for DPP-4 inhibition by sitagliptin. Given a mean residence time for ApoC1 of $3.7+0.3$ days [28], or a half-life of 2.56 days, full inhibition of DPP-4 should result in a 50\% decline of truncated protein in approximately 2.56 days. Assuming first-order kinetics with respect to ApoC1 and DPP-4, fifty percent decline in 3.0 days corresponded to approximately $85 \%$ inhibition of DPP-4, very nearly the target for drug administration [29].

Although the role of truncation is not known, several suggestions indicate that further study is warranted. It is also possible that measuring the truncation level of ApoC1 could be used to monitor drug efficacy in individual patients, similar to how glycation of hemoglobin (hemoglobin A1c) is used to monitor blood glucose levels over time in diabetic patients.

\section{CONCLUSION}

In this study we sought to determine if oral administration of sitagliptin altered the proportion of ApoC1 isoforms circulating in humans. Results indicated a dramatic change in
ApoC1 truncation, consistent with a high level of DPP-4 inhibition by sitagliptin.

\section{ACKNOWLEDGMENTS}

The authors thank Shannon Smith at the University of Minnesota for her technical assistance. Financial support for this study and article processing charges came from institutional funds from the University of Minnesota, Minneapolis, MN, USA awarded to ERS. All named authors meet the International Committee of Medical Journal Editors (ICMJE) criteria for authorship for this manuscript, take responsibility for the integrity of the work as a whole, and have given final approval to the version to be published.

Conflict of interest. NEBS, MSW, JAK, and GLN have no conflicts to disclose. ERS has served as a consultant to Sanofi, Novo Nordisk, Merck, and Eli Lilly, and has received grant funding from Eli Lilly for unrelated studies.

Compliance with ethics guidelines. This study was approved by the Institutional Review Board of the University of Minnesota. All procedures followed were in accordance with the ethical standards of the responsible committee on human experimentation at the University of Minnesota and with the Helsinki Declaration of 1975, as revised in 2013. Informed consent was obtained from all patients for being included in the study.

Open Access. This article is distributed under the terms of the Creative Commons Attribution Noncommercial License which permits any noncommercial use, distribution, and reproduction in any medium, provided the original author(s) and the source are credited. 


\section{REFERENCES}

1. Poensgen J. Apolipoprotein C-1 inhibits the hydrolysis by phospholipase A2 of phospholipids in liposomes and cell membranes. Biochim Biophys Acta. 1990;1042(2):188-92.

2. Berbee JF, van der Hoogt CC, Sundararaman D, Havekes LM, Rensen PC. Severe hypertriglyceridemia in human APOC1 transgenic mice is caused by apoC-I-induced inhibition of LPL. J Lipid Res. 2005;46(2):297-306.

3. Conde-Knape K, Bensadoun A, Sobel JH, Cohn JS, Shachter NS. Overexpression of apoC-I in apoEnull mice: severe hypertriglyceridemia due to inhibition of hepatic lipase. J Lipid Res. 2002;43(12):2136-45.

4. Sehayek E, Eisenberg S. Mechanisms of inhibition by apolipoprotein $\mathrm{C}$ of apolipoprotein E-dependent cellular metabolism of human triglyceride-rich lipoproteins through the low density lipoprotein receptor pathway. J Biol Chem. 1991;266(27):18259-67.

5. Weisgraber KH, Mahley RW, Kowal RC, Herz J, Goldstein JL, Brown MS. Apolipoprotein C-I modulates the interaction of apolipoprotein $\mathrm{E}$ with beta-migrating very low density lipoproteins (beta-VLDL) and inhibits binding of beta-VLDL to low density lipoprotein receptor-related protein. J Biol Chem. 1990;265(36):22453-9.

6. Kushwaha RS, Hasan SQ, McGill HC Jr, Getz GS, Dunham RG, Kanda P. Characterization of cholesteryl ester transfer protein inhibitor from plasma of baboons (Papio sp.). J Lipid Res. 1993;34(8):1285-97.

7. Muurling M, van den Hoek AM, Mensink RP, Pijl H, Romijn JA, Havekes LM, Voshol PJ. Overexpression of APOC1 in obob mice leads to hepatic steatosis and severe hepatic insulin resistance. J Lipid Res. 2004;45(1):9-16.

8. Anuurad E, Yamasaki M, Shachter N, Pearson TA, Berglund L. ApoE and ApoC-I polymorphisms: association of genotype with cardiovascular disease phenotype in African Americans. J Lipid Res. 2009;50(7):1472-8.

9. Gao L, Gabriel C, Lavoie T, Ye SQ. An improved RSP method to detect HpaI polymorphism in the apolipoprotein C-1 gene promoter. BMC Med Genet. 2002;3:13.

10. Retz W, Thome J, Durany N, Harsanyi A, RetzJunginger $\mathrm{P}$, Kornhuber J, Riederer $\mathrm{P}$, Rosler $\mathrm{M}$. Potential genetic markers of sporadic Alzheimer's dementia. Psychiatr Genet. 2001;11(3):115-22.
11. Shachter NS, Rabinowitz D, Stohl S, Conde-Knape K, Cohn JS, Deckelbaum RJ, Berglund L, Shea S. The common insertional polymorphism in the APOC1 promoter is associated with serum apolipoprotein C-I levels in Hispanic children. Atherosclerosis. 2005;179(2):387-93.

12. Smit M, van der Kooij-Meijs E, Woudt LP, Havekes LM, Frants RR. Exact localization of the familial dysbetalipoproteinemia associated $\mathrm{HpaI}$ restriction site in the promoter region of the APOC1 gene. Biochem Biophys Res Commun. 1988;152(3):1282-8.

13. Nelsestuen GL, Zhang Y, Martinez MB, Key NS, Jilma B, Verneris M, Sinaiko A, Kasthuri RS. Plasma protein profiling: unique and stable features of individuals. Proteomics. 2005;5(15):4012-24.

14. Bondarenko PV, Cockrill SL, Watkins LK, Cruzado ID, Macfarlane RD. Mass spectral study of polymorphism of the apolipoproteins of very low density lipoprotein. J Lipid Res. 1999; 40(3):543-55.

15. Rozek A, Sparrow JT, Weisgraber KH, Cushley RJ. Sequence-specific $1 \mathrm{H}$ NMR resonance assignments and secondary structure of human apolipoprotein C-I in the presence of sodium dodecyl sulfate. Biochem Cell Biol. 1998;76(2-3):267-75.

16. Wroblewski MS, Wilson-Grady JT, Martinez MB, Kasthuri RS, McMillan KR, Flood-Urdangarin C, Nelsestuen GL. A functional polymorphism of apolipoprotein $\mathrm{C} 1$ detected by mass spectrometry. FEBS J. 2006;273(20):4707-15.

17. Lahiry P, Cao H, Ban MR, Pollex RL, Mamakeesick M, Zinman B, Harris SB, Hanley AJ, Huff MW, Connelly PW, Hegele RA. APOC1 T45S polymorphism is associated with reduced obesity indices and lower plasma concentrations of leptin and apolipoprotein C-I in aboriginal Canadians. J Lipid Res. 2010;51(4):843-8.

18. Kasthuri RS, McMillan KR, Flood-Urdangarin C, Harvey SB, Wilson-Grady JT, Nelsestuen GL. Correlation of a T45S variant of apolipoprotein C1 with elevated BMI in persons of American Indian and Mexican ancestries. Int $\mathrm{J}$ Obes (Lond). 2007;31(8):1334-6.

19. Shi J, Zhang S, Ma C, Liu X, Li T, Tang M, Han H, Guo Y, Zhao J, Zheng K, Kong X, Zhang K, Su Z, Zhao Z. Association between apolipoprotein CI HpaI polymorphism and sporadic Alzheimer's disease in Chinese. Acta Neurol Scand. 2004;109(2):140-5.

20. Mentlein R. Dipeptidyl-peptidase IV (CD26)-role in the inactivation of regulatory peptides. Regul Pept. 1999;85(1):9-24. 
21. Lambeir AM, Proost P, Durinx C, Bal G, Senten K, Augustyns K, Scharpe S, Van Damme J, De Meester I. Kinetic investigation of chemokine truncation by CD26/dipeptidyl peptidase IV reveals a striking selectivity within the chemokine family. J Biol Chem. 2001;276(32):29839-45.

22. Lambeir AM, Proost P, Scharpe S, De Meester I. A kinetic study of glucagon-like peptide-1 and glucagon-like peptide- 2 truncation by dipeptidyl peptidase IV, in vitro. Biochem Pharmacol. 2002;64(12):1753-6.

23. Chen $X$. Biochemical properties of recombinant prolyl dipeptidases DPP-IV and DPP8. Adv Exp Med Biol. 2006;575:27-32.

24. Raz I, Hanefeld M, Xu L, Caria C, Williams-Herman D, Khatami H. Efficacy and safety of the dipeptidyl peptidase-4 inhibitor sitagliptin as monotherapy in patients with type 2 diabetes mellitus. Diabetologia. 2006;49(11):2564-71.

25. Nelsestuen GL, Harvey SB, Zhang Y, Kasthuri RS, Sinaiko AR, Ely EW, Bernard GR, Homoncik M, Jilma B. Top-down proteomic analysis by MALDITOF profiling: concentration-independent biomarkers. Proteomics Clin Appl. 2008;2(2):158-66.

26. Puppione DL, Yam LM, Bassilian S, Souda P, Castellani LW, Schumaker VN, Whitelegge JP.
Mass spectral analysis of the apolipoproteins on mouse high density lipoproteins. Detection of posttranslational modifications. Biochim Biophys Acta. 2006;1764(8):1363-71.

27. Puppione DL, Bassilian S, Souda P, MacDonald MH, Halgand F, Whitelegge JP. Mass spectral analysis of the apolipoproteins on dog (Canis lupus familiaris) high density lipoproteins. Detection of apolipoprotein A-II. Comp Biochem Physiol Part D Genomics Proteomics. 2008;3(4):290-6.

28. Cohn JS, Batal R, Tremblay M, Jacques H, Veilleux L, Rodriguez C, Mamer O, Davignon J. Plasma turnover of HDL apoC-I, apoC-III, and apoE in humans: in vivo evidence for a link between HDL apoC-III and apoA-I metabolism. J Lipid Res. 2003;44(10):1976-83.

29. Herman GA, Stevens C, Van Dyck K, Bergman A, Yi B, De Smet M, Snyder K, Hilliard D, Tanen M, Tanaka W, Wang AQ, Zeng W, Musson D, Winchell G, Davies MJ, Ramael S, Gottesdiener KM, Wagner JA. Pharmacokinetics and pharmacodynamics of sitagliptin, an inhibitor of dipeptidyl peptidase IV, in healthy subjects: results from two randomized, double-blind, placebo-controlled studies with single oral doses. Clin Pharmacol Ther. 2005;78(6):675-88. 